UZZO, R.P.; BOVI, M.L.A.; SPIERING, S.H.; SÁES, L.A. Coeficiente de caminhamento entre caracteres vegetativos e de produção de palmito da palmeira real australiana. Horticultura Brasileira, Brasília, v.21, n.1, p. 136-142, jan-mar 2004.

\title{
Coeficiente de caminhamento entre caracteres vegetativos e de produção de palmito da palmeira real australiana
}

\author{
Roberta Pierry Uzzo'; Marilene L.A. Bovi; Sandra Heiden Spiering; Luís Alberto Sáes \\ Instituto Agronômico, C. Postal. 28, 13001-970 Campinas-SP;' bolsista mestrado da FAPESP; E-mail: rpuzzo@uol.com.br
}

\section{RESUMO}

A determinação do coeficiente de caminhamento é bastante útil no melhoramento genético de plantas perenes. No presente estudo foram estimados os efeitos diretos e indiretos de cinco caracteres vegetativos da planta, relacionados ao crescimento, sobre os principais componentes da produção de palmito da palmeira real australiana (Archontophoenix alexandrae Wendl. \& Drude), por meio do coeficiente de caminhamento. Para tanto, foram utilizados dados obtidos por ocasião da colheita realizada em 238 plantas de um experimento, com três de anos de campo, conduzido em PariqueraAçu, SP. Desdobraram-se as correlações lineares simples existentes entre as variáveis padronizadas (dependentes e independentes), estabelecendo-se posteriormente um diagrama causal e identificandose as inter-relações entre as variáveis envolvidas. Concluiu-se que o comprimento da folha flecha apresentou efeitos diretos e indiretos negativos e de baixa magnitude, evidenciando pouca influência na seleção de genótipos superiores, mas permitindo estabelecer, na prática, ponto adequado de colheita para maior retorno econômico. A maior magnitude dos coeficientes foi encontrada para a altura da planta, com efeitos diretos e indiretos elevados, positivos e significativos, explicando $85 \%$ da produção total. O diâmetro da planta, o número de folhas e o comprimento da quarta folha apresentaram efeitos diretos de baixa magnitude, porém positivos, podendo ser levados em consideração quando do estabelecimento de índices de seleção.

Palavras-chave: Archontophoenix alexandrae, caracteres agronômicos, coeficiente de trilha, melhoramento genético.

\begin{abstract}
Path coefficient analysis between vegetative and heart-ofpalm yield traits in Australian King palm

Path coefficient is a useful technique in perennial plant breeding. Direct and indirect effects of five growth related vegetative traits, over the main heart-of-palm yield components from King palm (Archontophoenix alexandrae Wendl. \& Drude) were estimated by path analysis. Harvesting data from 238 (three-year old) plants cultivated in an experiment carried out at Pariquera-Açu, São Paulo State, Brazil, were utilized. A casual diagram was established, and linear and simple standardized correlations were estimated in order to identify the interrelations between dependent and independent variables. Spear length showed small and negative direct and indirect effects, with low contribution to superior genotypes selection, although of practical importance to determine adequate harvesting timing for maximal economical value in this palm. The highest magnitude was found for plant height, with positive and significant direct and indirect effects, explaining $85 \%$ of the total yield. Plant diameter, leaf number and leaf size presented direct effects of low magnitude, although positive, should be considered only for selection indices establishment.
\end{abstract}

Keywords: Archontophoenix alexandrae, agronomic characters, genetic improvement, path coefficient.

\section{(Recebido para publicação em 1 de julho de 2003 e aceito em 19 de dezembro de 2003)}

\begin{abstract}
A palmeira real australiana (Archontophoenix spp.), conhecida também como Seafortia devido ao antigo nome do gênero, vem ganhando a atenção de pesquisadores e produtores para a produção de palmito. O gênero Archontophoenix, originário do leste da Austrália, é amplamente utilizado em praças e jardins ao redor do mundo como planta ornamental. Além da alta germinação, da resistência às principais doenças que ocorrem em viveiro e do rápido crescimento das plantas, chama a atenção a qualidade do palmito produzido por palmeiras desse gênero.

Pesquisas recentes mostraram que a palmeira real australiana possui elevado potencial para produção de palmito de qualidade e atestam a viabilidade de
\end{abstract}

seu cultivo em nosso meio (Ramos et al., 1997; Bovi, 1998; Berbari et al., 2003; Bovi et al., 2003). A produção de palmito nas espécies do gênero pode ser feita já a partir de 22 meses de campo, desde que cultivadas em regiões aptas e com adubação apropriada (Bovi et al., 2001; Chaimsohn, 2001).

Não obstante a importância da palmeira real australiana, tanto como ornamental quanto como produtora de palmito de qualidade, a revisão de literatura revelou que são escassos os trabalhos científicos com esse gênero. No período de 1990 a 2003 foram encontrados apenas 25 trabalhos indexados, a maioria deles simples relatos de ocorrência de doenças. Na verdade, há carência de estudos com palmeiras em to- das as áreas de conhecimento, provavelmente devido às dificuldades logísticas existentes por serem plantas perenes, de ciclo longo e grande altura.

Dada a ausência de estudos com Archontophoenix, reconhece-se que o melhoramento do gênero poderia em muito contribuir para aumentar o potencial de uso das espécies. Um dos parâmetros indispensáveis para o melhoramento de qualquer espécie é o conhecimento de correlações entre caracteres de interesse, por permitir subsídios para a seleção ou descarte de materiais genéticos (Goldenberg, 1968; Simmonds, 1979). No entanto, a correlação entre caracteres agronômicos, ainda que seja de grande utilidade na determinação dos componentes de um ca- 
ráter complexo, como o palmito, não dá a exata importância relativa das influências diretas e indiretas desses caracteres na produção.

O coeficiente de trilha ou de caminhamento ("path coefficient"), proposto originalmente por Wright (1921), permite desdobrar o coeficiente de correlação em efeitos diretos e indiretos e estudar a ação de componentes específicos que produzem uma certa relação entre variáveis correlacionadas. Dewey e Lu (1959) foram os primeiros autores a demonstrar o uso desse coeficiente em estudos de inter-relacionamento de caracteres agronômicos desejáveis. Embora estabelecido há tantos anos, ainda hoje em dia o uso dessa análise vem sendo de grande utilidade no melhoramento de plantas, especialmente em palmeiras, como atestam os relatos de Moreira (1998) e Oliveira et al. (2000) em açaizeiro (Euterpe oleracea Mart.); Bhagavan e Nair (1989) em areca (Areca catechu L.); Prabhakaran et al. (1991) e Sindhumole e Ibrahim (2002) em coqueiro (Cocos nucifera L.); Taniputra e Manurung (1988), Oboh e Fakorede (1990), Ataga (1995) e Oboh e Fakorede (1999) em dendezeiro (Elaeis guineensis Jacq.).

A correta aplicação do coeficiente de caminhamento é dependente do conjunto de caracteres estudados e da confecção de um diagrama de trilha adequado, inter-relacionando esses caracteres. Para tanto, é essencial a experiência do pesquisador na espécie em estudo, bem como na definição e avaliação dos possíveis caracteres diretos e indiretos de importância para o material em uso (Dewey e Lu, 1959). Segundo esses autores, a análise de trilha, nos casos em que se considera um único modelo causal, é simplesmente uma análise de regressão parcial padronizada, sendo útil no desdobramento dos coeficientes de correlação em efeitos diretos e indiretos. No entanto, como alertado por Cruz e Regazzi (1994), é comum o uso de vários diagramas causais, especialmente em programas de melhoramento, visto que sempre é possível desdobrar as variáveis em componentes primários e secundários da produção. Esse tipo de análise, conhecida como análise de trilha com diagramas em cadeia, é uma expansão da regressão múltipla, visto que estão envolvidas inter-relações complexas.

O objetivo deste trabalho foi estimar, por meio de análise de trilha com diagrama em cadeia, os efeitos diretos e indiretos de caracteres relacionados ao crescimento (secundários) sobre caracteres componentes da produção de palmito (primários), de forma a obter subsídios para o melhoramento genético de palmeiras da espécie Archontophoenix alexandrae.

\section{MATERIAL E MÉTODOS}

Foram utilizadas 238 plantas selecionadas ao acaso dentro de população de palmeira real australiana (Archontophoenix alexandrae Wendl e Drude), com 36 meses, em cultivo em

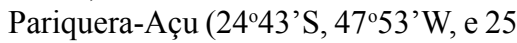
$\mathrm{m}$ anm), SP. O clima da região é mesotérmico, tropical, quente e úmido, com temperatura média anual de $21,8^{\circ} \mathrm{C}$, precipitação pluviométrica anual de $1.587 \mathrm{~mm}$ e evapotranspiração de 1.140 mm (Lepsch et al., 1990). O solo da área experimental é um Cambissolo Háplico Distrófico, moderadamente ácido, com teores de $\mathrm{Ca}$ e $\mathrm{K}$ baixos, mas com $\mathrm{Mg}$ relativamente alto, profundo, com drenagem moderada, relevo quase plano e saturação por bases entre 20 e $40 \%$ (Sáes, 1995).

O espaçamento adotado na cultura foi de $2 \times 0,75 \mathrm{~m}$, sendo o plantio efetuado com mudas com seis meses de idade, formadas em tubetes de $150 \mathrm{ml}$ com substrato comercial. Durante o plantio foi colocado $100 \mathrm{~g} /$ cova de superfosfato simples. A adubação mineral foi iniciada a partir do sexto mês de plantio, empregando $50 \mathrm{~g} /$ planta da fórmula NPK 20:5:20, aplicada em cobertura e em faixas, a cada três meses.

Antes da colheita, realizada aos 36 meses após o plantio, os seguintes caracteres vegetativos foram medidos, de acordo com o estabelecido por Clement e Bovi (2000): diâmetro da planta $(\mathrm{cm})$ a $10 \mathrm{~cm}$ acima da superfície do solo; altura da planta (cm), medida do solo até o ponto de inserção entre a flecha e a folha mais nova; número de folhas verdes completamente expandidas; comprimento $(\mathrm{cm})$ da ráquis foliar da quarta folha (folha +4 ), medido do ponto de emissão dos folíolos até a bifurcação deles no ápice; comprimento (cm) da folha flecha (folha 0 ), medido do ponto de emissão da folha 0 na haste até o ápice da folha.

Os caracteres acima foram selecionados pela facilidade de mensuração, e muitos deles, por ter apresentado boa correlação com o palmito de palmeiras de outros gêneros botânicos (Bovi et al., 1990; 1991; 1993a; Fantini et al., 1997; Reis et al., 1999).

Após as mensurações, executou-se o corte da porção apical da palmeira (capitel) no local da amostragem, levando-se as plantas etiquetadas ao laboratório, onde se realizou a seguinte avaliação, de acordo com o estabelecido por Clement e Bovi (2000): peso (massa) do palmito basal $(\mathrm{g})$, também conhecido como coração ou resíduo basal, e constituído pela porção macia do estipe localizada logo abaixo do meristema e que é bastante tenro para ser consumido in natura; diâmetro do palmito (mm), avaliado como o diâmetro médio dos $n$ toletes de palmito tipo exportação; comprimento do palmito $(\mathrm{cm})$ do tipo exportação, avaliado com o número de toletes inteiros de palmito multiplicados por $9 \mathrm{~cm}$ (tamanho padrão); peso (massa) do palmito (g) exclusivamente do tipo exportação; peso (massa) do palmito apical $(\mathrm{g})$, também conhecido como banda, correspondendo à porção apical, ainda macia, mas não envolta por bainha foliar; peso (massa) total (g), somatório de palmito basal, exportação e apical.

Efetuou-se a padronização das variáveis avaliadas, dividindo-se o desvio de cada observação em relação à média pelo desvio-padrão da amostra, de forma a poder comparar efeitos de caracteres mensuráveis em diferentes escalas. Correlações lineares simples foram obtidas pelo método de Pearson (Steel e Torrie, 1980), usando-se as variáveis padronizadas. A estimativa dos coeficientes de trilha (efeitos diretos e indiretos) foi feita considerando-se uma variável básica Y (produto total), a ação de três variáveis principais explicativas, componentes diretas da produção (palmito basal, exportação e apical) e cinco variáveis secundárias explicativas, referentes ao crescimento da planta (diâme- 


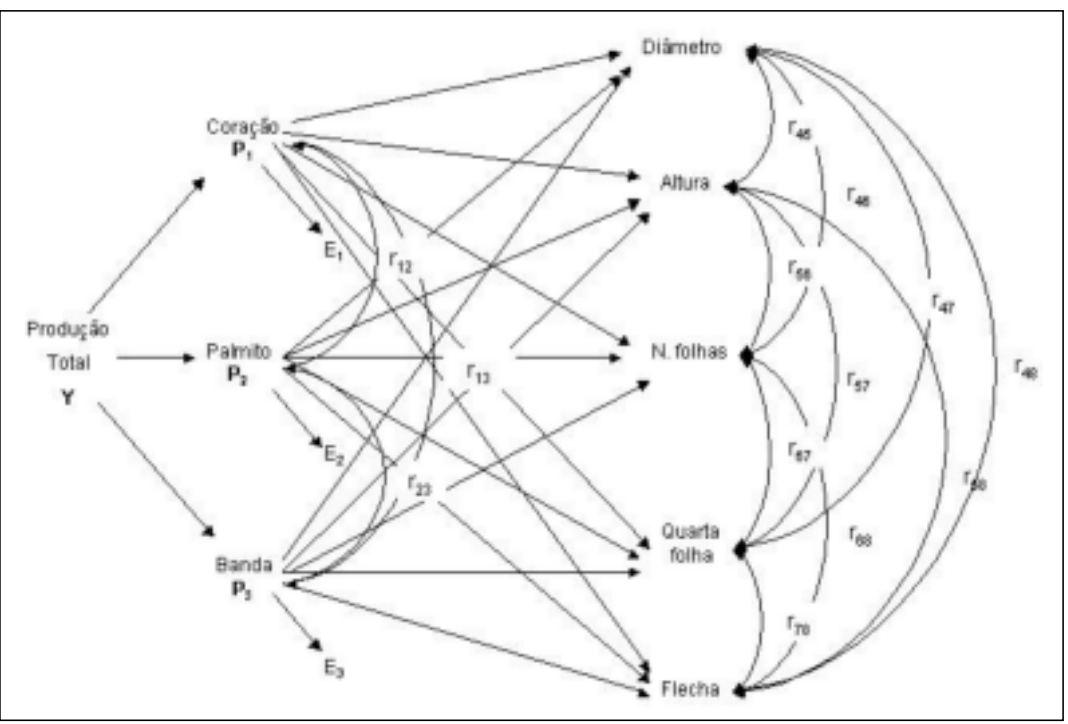

Figura 1. Diagrama causal, em cadeia, dos efeitos diretos e indiretos dos componentes secundários (diâmetro, altura, número de folhas, comprimento da quarta folha e comprimento da folha flecha) sobre os componentes primários (palmito basal - $\mathbf{P}_{1}$, palmito tipo exportação $-\mathbf{P}_{2}$, palmito apical $-\mathbf{P}_{3}$ ) da produção total de palmito $(\mathbf{Y})$ da palmeira real australiana. Campinas, IAC, 2001.

tro, altura, número de folhas, comprimento da quarta folha e comprimento da folha flecha). Foi estabelecido um diagrama causal em cadeia, mostrando as inter-relações entre as variáveis envolvidas (Figura 1). O diagrama foi construído com base no método descrito por Cruz e Regazzi (1994) e levando-se em consideração a relação lógica, aditiva, entre as variáveis. No diagra$\mathrm{ma}$, as setas unidirecionais indicam a influência direta de cada uma das variáveis explicativas, medidas pelo coeficiente de caminhamento $\left(\mathrm{p}_{\mathrm{j} y}\right)$. As setas bidirecionais mostram a interdependência dos componentes, cuja magnitude e direção são dadas pelo coeficiente de correlação simples $\left(\mathrm{r}_{\mathrm{ij}}\right)$. Nessa mesma figura, $\mathrm{E}_{1}, \mathrm{E}_{2} \mathrm{e} \mathrm{E}_{3}$ sã̃o as variáveis residuais referentes aos caracteres principais: peso do palmito basal $\left(\mathrm{P}_{1}\right)$, peso do palmito tipo exportação $\left(\mathrm{P}_{2}\right)$ e peso do palmito apical $\left(\mathrm{P}_{3}\right)$, respectivamente, o que permite a completa determinação de todos os efeitos.

Seguindo o diagrama causal, as correlações fenotípicas padronizadas foram partilhadas em componentes de efeitos diretos $\left(\mathrm{p}_{\mathrm{iy}}\right)$ e componentes de efeitos indiretos $\left(\mathrm{r}_{\mathrm{ij}} \mathrm{p}_{\mathrm{jy}}\right)$, de acordo com o modelo de caracteres primários e secundários que explicam a variação em Y (produto total); onde $r_{i j}$ é o coeficiente de correlação do caráter i com $\mathrm{j}$; e $\mathrm{p}_{\mathrm{jy}}$ é o efeito direto (ou coeficiente de caminhamento) do caráter $\mathrm{j}$ sobre o produto final, $\mathrm{Y}$.

As equações seguintes expressam as relações básicas entre coeficientes de correlação e de caminhamento para o modelo explicativo envolvendo apenas os efeitos dos caracteres primários $\left(\mathrm{P}_{1}\right.$, $\mathrm{P}_{2}$ e $\mathrm{P}_{3}$ ) sobre a produção total $(\mathrm{Y})$ :

$$
\begin{aligned}
& r_{1 y}=p_{1 y}+r_{12} p_{2 y}+r_{13} p_{3 y} \\
& r_{2 y}=r_{21} p_{1 y}+p_{2 y}+r_{23} p_{3 y} \\
& r_{3 y}=r_{31} p_{1 y}+r_{32} p_{2 y}+p_{3 y}
\end{aligned}
$$

A resolução do sistema de equações acima foi efetuada por cálculo matricial, conforme proposto por Cruz e Regazzi (1994).

Por meio dos efeitos diretos e indiretos, inclusive do efeito residual total $\left(\mathrm{E}_{4 \mathrm{y}}=\mathrm{E}_{1}+\mathrm{E}_{2}+\mathrm{E}_{3}\right)$, obteve-se a equação de determinação total de magnitude igual a 1. A relação entre o efeito residual $\left(\mathrm{E}_{4 \mathrm{y}}\right)$ e o coeficiente de determinação da análise de caminhamento $\left(\mathrm{R}_{\mathrm{y}(1,2,3)}^{2}\right)$ é dada pela expressão:

$$
\mathrm{E}_{4 \mathrm{y}}=\left[1-\mathrm{R}_{\mathrm{y}(1,2,3)}^{2}\right]^{1 / 2}
$$

Seguindo o mesmo raciocínio, foram estabelecidas, separadamente, as relações entre os caracteres secundários (diâ- metro, altura, número de folhas, comprimento da quarta folha e comprimento da folha flecha) e os diferentes componentes primários da produção (palmito basal, tipo exportação e apical). Visando elucidar as relações entre alguns caracteres referentes ao crescimento da planta e o diâmetro e o comprimento do palmito exportação, equações complementares, envolvendo essas variáveis, foram desenvolvidas. Todas as análises foram efetuadas com o auxílio do programa SAEG (SAEG-UFV, 1997).

\section{RESULTADOS E DISCUSSÃO}

Os componentes diretos da produção de palmito de palmeiras são: o palmito basal, também conhecido como resíduo basal ou coração e que se caracteriza pela porção macia do estipe; 0 palmito tipo exportação que corresponde ao palmito propriamente dito, sendo composto por toletes completos e perfeitos; e o palmito apical, conhecido como banda, que é a porção apical do palmito, sendo constituída pela parte macia, mas desprovida de bainha externa protetora (Ferreira et al., 1982a; Clement e Bovi, 2000). Esses componentes apresentam valores econômicos diferenciados no mercado, com o palmito tipo exportação (em toletes) valendo, normalmente, o dobro das porções basal e apical.

Em algumas espécies de crescimento lento, tais como as do gênero Euterpe, é pequena a contribuição do palmito basal para a produção total (Ferreira et $a l .$, 1982a). Já em espécies de rápido crescimento, como as do gênero Bactris, essa porção é bastante significativa (Ferreira et al., 1982b; Bovi et al., 1992; Mora-Urpí et al., 1997). Nota-se, pela tabela 1, que o mesmo acontece com a espécie Archontophoenix alexandrae.

A soma dos efeitos direto e indireto do palmito basal foi superior à do palmito exportação $(0,92$ e 0,82 , respectivamente), indicando que a contribuição da porção macia do estipe para a produção total comercial é significativa, sendo superior às demais partes. Os efeitos direto $(0,20)$ e indiretos do palmito apical (variando de 0,03 a 0,08 ) são pequenos e negligíveis, podendo-se aventar que a avaliação desse componente pouco contribui para a produção total. 
Tabela 1. Estimativas dos efeitos diretos e indiretos de três componentes primários da produção (palmito basal, tipo exportação e apical) sobre a massa total de palmito de palmeira real australiana. Campinas, IAC, 2001.

\begin{tabular}{lccccc}
\hline \multirow{2}{*}{ Caráter } & Efeito direto & \multicolumn{3}{c}{ Efeitos indiretos } & Produção \\
\cline { 3 - 5 } & & Palmito basal & $\begin{array}{c}\text { Palmito } \\
\text { exportação }\end{array}$ & Palmito apical & total \\
\hline Palmito basal & 0,5737 & & 0,2629 & 0,0813 & 0,9178 \\
Palmito exportação & 0,4564 & 0,3304 & & 0,0293 & 0,8161 \\
Palmito apical & 0,2024 & 0,2303 & 0,0660 & & 0,4987 \\
\hline
\end{tabular}

Tabela 2. Estimativas dos efeitos diretos e indiretos dos caracteres vegetativos diâmetro, altura, número de folhas, comprimento da quarta folha e comprimento da folha flecha sobre a massa total de palmito basal, palmito tipo exportação, palmito apical e palmito total (basal+exportação+apical) de palmeira real australiana. Campinas, IAC, 2001.

\begin{tabular}{|c|c|c|c|c|c|c|c|}
\hline \multirow{2}{*}{ Caráter } & \multirow{2}{*}{$\begin{array}{l}\text { Efeito } \\
\text { direto }\end{array}$} & \multicolumn{5}{|c|}{ Efeitos indiretos } & \multirow{2}{*}{$\begin{array}{c}\text { Efeitos } \\
\text { totais }\end{array}$} \\
\hline & & Diâm. & Altura & Folha & Quar. & Flecha & \\
\hline \multicolumn{8}{|c|}{ Palmito basal } \\
\hline Diâmetro & $-0,0128$ & & 0,3933 & 0,1069 & 0,1533 & 0,0406 & 0,6814 \\
\hline Altura & 0,4415 & $-0,0114$ & & 0,1130 & 0,1533 & 0,0410 & 0,7375 \\
\hline Núm. folhas & 0,1678 & $-0,0081$ & 0,2974 & & 0,0965 & 0,0280 & 0,5816 \\
\hline Quarta folha & 0,1828 & $-0,0107$ & 0,3703 & 0,0886 & & 0,0390 & 0,6700 \\
\hline Comp. flecha & 0,0619 & $-0,0084$ & 0,2925 & 0,0760 & 0,1151 & & 0,5371 \\
\hline \multicolumn{8}{|c|}{ Palmito tipo exportação } \\
\hline Diâmetro & 0,2561 & & 0,50001 & 0,0553 & 0,0337 & $-0,1198$ & 0,7254 \\
\hline Altura & 0,5614 & 0,2281 & & 0,0585 & 0,0338 & $-0,1209$ & 0,7609 \\
\hline Núm. folhas & 0,0868 & 0,1632 & 0,3782 & & 0,0212 & $-0,0827$ & 0,5668 \\
\hline Quarta folha & 0,0402 & 0,2147 & 0,4709 & 0,0458 & & $-0,1149$ & 0,6568 \\
\hline Comp. flecha & $-0,1825$ & 0,1682 & 0,3719 & 0,0393 & 0,0253 & & 0,4223 \\
\hline \multicolumn{8}{|c|}{ Palmito apical } \\
\hline Diâmetro & 0,3685 & & $-0,2766$ & 0,1286 & 0,0060 & 0,2491 & 0,4756 \\
\hline Altura & $-0,3105$ & 0,3282 & & 0,1359 & 0,0060 & 0,2512 & 0,4108 \\
\hline Núm. folhas & 0,2017 & 0,2349 & $-0,2092$ & & 0,0038 & 0,1718 & 0,4030 \\
\hline Quarta folha & 0,0072 & 0,3090 & $-0,2604$ & 0,1065 & & 0,2388 & 0,4011 \\
\hline Comp. flecha & 0,3792 & 0,2420 & $-0,2057$ & 0,0914 & 0,0045 & & 0,5115 \\
\hline \multicolumn{8}{|c|}{ Produção total de palmito } \\
\hline Diâmetro & 0,1841 & & 0,3979 & 0,1126 & 0,1046 & 0,0190 & 0,8182 \\
\hline Altura & 0,4467 & 0,1640 & & 0,1190 & 0,1046 & 0,0192 & 0,8535 \\
\hline Núm. folhas & 0,1767 & 0,1174 & 0,3009 & & 0,0658 & 0,0131 & 0,6739 \\
\hline Quarta folha & 0,1247 & 0,1544 & 0,3746 & 0,0933 & & 0,0182 & 0,7653 \\
\hline Comp. flecha & 0,0290 & 0,1209 & 0,2959 & 0,0800 & 0,0785 & & 0,6044 \\
\hline
\end{tabular}

As estimativas dos efeitos diretos e indiretos dos cinco caracteres relacionados ao crescimento da planta sobre o palmito basal encontram-se na tabela 2 . Observa-se que a característica que mais afeta o rendimento desse componente é a altura da planta, com efeitos direto e indiretos positivos e de magnitude razoável quando comparada aos efeitos das demais. Os resultados indicam que altura da planta por ocasião da colheita de palmito é responsável por cerca de $74 \%$ da variação da massa do palmito basal. Resultados semelhantes podem ser observados quando se avalia os efeitos diretos e indiretos dos caracteres da planta sobre a massa de palmito tipo exportação (tabela 2). Nota-se que, dentre os cinco caracteres, a altura da planta proporcionou efeitos diretos e indiretos de boa magnitude, superiores aos obtidos quando da avaliação do palmito basal. É marcante seu efeito indireto sobre todos os caracteres vegetativos avaliados, especialmente sobre o diâmetro da planta. A altura da planta foi responsável por $76 \%$ da variação encon- 
Tabela 3. Estimativas dos efeitos diretos e indiretos dos caracteres vegetativos diâmetro, altura, número de folhas, comprimento da quarta folha $\mathrm{e}$ comprimento da folha flecha sobre o diâmetro e o comprimento do palmito tipo exportação de palmeira real australiana. Campinas, IAC, 2001.

\begin{tabular}{|c|c|c|c|c|c|c|c|}
\hline \multirow{2}{*}{ Caráter } & \multirow{2}{*}{$\begin{array}{l}\text { Efeito } \\
\text { direto }\end{array}$} & \multicolumn{5}{|c|}{ Efeitos indiretos } & \multirow{2}{*}{$\begin{array}{c}\text { Efeitos } \\
\text { totais }\end{array}$} \\
\hline & & Diâm. & Altura & Folha & Quar. & Flecha & \\
\hline \multicolumn{8}{|c|}{ Diâmetro do palmito exportação } \\
\hline Diâmetro & 0,4489 & & 0,1101 & 0,0838 & 0,1472 & $-0,0626$ & 0,7274 \\
\hline Altura & 0,1236 & 0,3999 & & 0,0886 & 0,1472 & $-0,0632$ & 0,6962 \\
\hline Núm. folhas & 0,1315 & 0,2861 & 0,0833 & & 0,0927 & $-0,0432$ & 0,5504 \\
\hline Quarta folha & 0,1755 & 0,3764 & 0,1037 & 0,0695 & & $-0,0601$ & 0,6651 \\
\hline Comp. flecha & $-0,0954$ & 0,2949 & 0,0819 & 0,0596 & 0,1105 & & 0,4515 \\
\hline \multicolumn{8}{|c|}{ Comprimento do palmito exportação } \\
\hline Diâmetro & $-0,1114$ & & 0,6000 & 0,0056 & 0,1481 & $-0,2068$ & 0,4355 \\
\hline Altura & 0,6767 & $-0,0992$ & & 0,0059 & 0,1481 & $-0,2086$ & 0,5198 \\
\hline Núm. Folhas & 0,0088 & $-0,0710$ & 0,4538 & & 0,0932 & $-0,1427$ & 0,3421 \\
\hline Quarta folha & 0,1766 & $-0,0934$ & 0,5650 & 0,0046 & & $-0,1983$ & 0,4545 \\
\hline Comp. flecha & $-0,3149$ & $-0,0731$ & 0,4462 & 0,0039 & 0,1112 & & 0,1733 \\
\hline
\end{tabular}

trada na massa do palmito exportação, revelando-se um caráter adequado para a avaliação indireta da produção de palmito em Archontophoenix, bem como para a seleção de plantas superiores para essa atividade agrícola. Para outras palmeiras, como areca e coqueiro, a altura também mostrou ser de utilidade para a seleção de plantas, por apresentar efeitos diretos positivos e altamente significativos sobre a produção, tanto de frutos (Bhagavan e Nair, 1989), quanto de óleo (Sindhumole e Ibrahim, 2002).

Embora o palmito apical tenha contribuído pouco para a produção total de palmito (apenas $20 \%$, considerando o efeito direto), a análise da partição dos efeitos dos caracteres vegetativos sobre ele mostra resultados interessantes (tabela 2). Não obstante a baixa magnitude de todos os coeficientes, evidenciase que a altura teve sempre efeitos negativos, tanto direto como indiretos, sobre a massa final de palmito apical. Deduz-se portanto que, na amostragem utilizada $(\mathrm{n}=238)$, com plantas com altura até a inserção da folha flecha variando de 0,28 a 3,20 m, quanto maior a altura da palmeira maior a produção de palmito tipo exportação, com conseqüente diminuição de produção de palmito apical, considerado sempre como porção de menor valor econômico. Por outro lado, foram positivos e comparativamente elevados, os efeitos direto $(0,37)$ e indiretos $(0,23$ a 0,33$)$ do diâ- metro da planta sobre esse componente da produção. É também especialmente notória a influência direta $(0,38)$ e indireta $(0,17$ a 0,25$)$ do comprimento da folha flecha sobre esse caráter. Não obstante, observa-se que o comprimento da flecha é responsável apenas por $51 \%$ da variação apresentada pelo palmito apical, enquanto para os demais valores entre 40 e $47 \%$ foram obtidos, indicando que a produção de palmito apical é influenciada por outros fatores não mensurados no presente estudo. No entanto, parece existir uma relação significativa e positiva entre comprimento da folha flecha (folha bandeira) e produção de palmito apical. Como a colheita de palmito é sempre escalonada e periódica, realizada com base no desenvolvimento vegetativo da planta (Bovi, 1998; Bovi et al., 2001), pode-se inferir que, na prática, para uma mesma altura de planta, deve-se dar preferência à colheita aquelas que apresentam menor comprimento da folha flecha por ocasião do corte.

Quando se avaliam os efeitos dos caracteres vegetativos sobre a produção total (tabela 2), nota-se que a influência da altura da planta é superior à do diâmetro, com efeitos direto e indiretos explicando $85 \%$ da variação em massa total. O efeito direto da altura foi 2,5 vezes superior ao efeito direto do diâmetro da planta. Isso indica a grande validade desse caráter para avaliação indireta da produção total, bem como para seleção de plantaselite para a produção de sementes, visando a produção de palmito. A importância da variável altura para a determinação do ponto de corte, bem como para a seleção de plantas-elite já foi reportada anteriormente por alguns autores para palmeiras produtoras de palmito (Bovi et al., 1992; Bovi et al., 1993a,b; Clement, 1995; Mora-Urpí et al., 1997), assim como para aquelas produtoras de fruto e de óleo (Bhagavan e Nair, 1989; Sindhumole e Ibrahim, 2002).

A produção de palmito tipo exportação é função do número (comprimento) e do diâmetro dos toletes (Ferreira et al., 1982a). Seguindo o mesmo esquema de partição, foi verificada a relação entre os caracteres vegetativos relacionados ao crescimento da palmeira e essas duas características (diagrama não apresentado). Observa-se na tabela 3, que o diâmetro da planta por ocasião do corte é a variável que mais interfere no diâmetro do palmito, com efeitos direto e indiretos de magnitude elevada, quando comparados aos efeitos das demais. Cerca de $73 \%$ da variação em diâmetro do palmito tipo exportação é explicada pelo diâmetro da planta por ocasião da colheita. $\mathrm{O}$ efeito direto do diâmetro da planta sobre o diâmetro do palmito foi 3,6 vezes superior ao efeito direto da altura sobre esse mesmo caráter.

Por outro lado, a altura da planta é a variável que maior influência direta tem 
sobre o comprimento total do palmito (tabela 3$)$, com efeito direto $(0,68)$ superior ao obtido em todas as análises anteriormente efetuadas (tabelas 1 e 2). Seus efeitos indiretos também foram de alta magnitude, quando comparados aos demais, variando de 0,45 a 0,60 . Fato interessante pode ser observado, ainda na tabela 3 , com relação aos efeitos do comprimento da folha flecha sobre o comprimento do palmito tipo exportação. Nota-se aqui efeitos negativos direto e indiretos dessa variável sobre o caráter em questão. A análise conjunta das tabelas 2 e 3 , evidencia que quanto maior o tamanho da folha flecha, menor o comprimento do palmito tipo exportação e conseqüentemente sua massa, e maior é a produção de palmito apical. Como o palmito tipo exportação tem um valor econômico superior sobre o palmito apical, e este representa em média apenas $9 \%$ da produção total, conclui-se que, independentemente da altura e do diâmetro da planta, deve-se fazer a colheita quando a folha flecha estiver pouco expandida. Dessa forma, o rendimento em palmito tipo exportação será maior. O conjunto das duas variáveis (altura e flecha) é de interesse prático, pois ambas podem ser visualmente estimadas com precisão suficiente pelo colhedor de palmito, auxiliando na determinação do ponto adequado de colheita da palmeira real australiana.

Os resultados indicam que além da altura, as variáveis correlacionadas diâmetro da planta, número de folhas e o comprimento da quarta folha podem ser usadas para aumentar as chances de seleção de plantas superiores. Em palmeiras de outras espécies, o número e o comprimento das folhas, bem como o número de folíolos nelas presentes, vêm sendo utilizados, separadamente ou em conjunto, como critério para seleção de plantas-elite e predição de produção de frutos (Taniputra e Manurung, 1998; Oboh e Fakorede, 1990; Prabhakaran et al., 1991). No entanto, o presente relato mostrou que a contribuição da quantidade e do comprimento de folhas é pequena, não valendo o esforço da medida. Recomenda-se utilizá-las apenas na construção de índices de seleção.

\section{AGRADECIMENTOS}

À Fundação de Amparo à Pesquisa do Estado de São Paulo pela concessão de bolsa de mestrado ao primeiro autor.

\section{LITERATURA CITADA}

ATAGA, C.D. Character interrelationships and path coefficient analysis for oil yield in the oil palm. Annals of Applied Biology, v.127, n.1, p.157162, 1995.

BHAGAVAN, S.; NAIR, B.P. Vigour index as an additional parameter in identifying elite palms in arecanut. Journal of Plantation Crops, v.16, Supl., p-389-394, 1989.

BERBARI, S.A.G.; BOVI, M.L.A.; VICENTE, E.; OLIVEIRA, L.A.T.T. Avaliação da qualidade do palmito da palmeira real australiana para industrialização. In: CONGRESSO BRASILEIRO DE OLERICULTURA, 43., 2003. Recife. Anais..., Brasília: SOB. 2003. 4 p. (CD-ROM).

BOVI, M.L.A. Cultivo da palmeira real australiana visando à produção de palmito. Campinas: InstitutoAgronômico, 1998.26 p. (Boletim Técnico 172). BOVI, M.L.A.; GODOY JR., G.; SPIERING, S.H.; CAMARGO, S.B. Relação entre caracteres da planta e do palmito de açaizeiros. Bragantia, Campinas, v.49, n.1, p.69-81,1990.

BOVI, M.L.A.; GODOY JR., G.; SÁES, L.A. Correlações fenotípicas entre caracteres da palmeira Euterpe edulis Mart. e produção de palmito. Revista Brasileira de Genética, Ribeirão Preto, v.14, n.1, p.105-121, 1991.

BOVI, M.L.A.; GODOY JR., G.; CAMARGO, S.B.; SPIERING, S.H. Caracteres indiretos na seleção de pupunheiras inermes (Bactris gasipaes H.B.K.) para palmito. In: IV CONGRESO INTERNACIONAL SOBRE BIOLOGIA, AGRONOMIA E INDUSTRIALIZACION DEL PIJUAYO, 4., Iquitos, 1993. Anais. San José, UFCR, 1993a. p.163-176.

BOVI, M.L.A.; GODOY JR., G.; CAMARGO, S.B.; SPIERING, S.H. Seleção precoce em pupunheiras (Bactris gasipaes H.B.K.) para produção de palmito. In: IV CONGRESO INTERNACIONAL SOBRE BIOLOGIA, AGRONOMIAE INDUSTRIALIZACION DEL PIJUAYO, 4., Iquitos, 1993. Anais. San José, UFCR, 1993b. p.177-195.

BOVI, M.L.A.; SÁES, L.A.; GODOY JR., G. Correlações fenotípicas entre caracteres não destrutíveis e palmito em pupunheiras. Revista Turrialba, v.42, n.3, p.382-390, 1992.

BOVI, M.L.A.; SÁES, L.A.; UZZO, R.P.; SPIERING, S.H. Adequate timing for heart-ofpalm harvesting in King palm. Horticultura Brasileira, Brasília, v.19, n.2, p.135-139, 2001.

BOVI, M.L.A.; GODOY JR., G; CEMBRANELLI, M.A.R.; SPIERING, S.H. Características físicas e produção de palmito de palmeira real australiana. In: CONGRESSO BRASILEIRO DE OLERICULTURA, 43., 2003. Recife. Anais..., Brasília: SOB. 2003. 4p. (CD-ROM).

CHAIMSOHN, F.P. Introdução ao cultivo da palmeira real australiana no Paraná. In: Curso sobre cultivo, processamento e comercialização de palmito de pupunha. Circular do Instituto Agronômico do Paraná, Londrina, 2001, n.117, 150 p. CLEMENT, C.R. Growth and genetic analysis of pejibaye (Bactris gasipaes Kunth, Palmae) in Hawaii. Honolulu: University of Hawaii, 1995. 221 p. (Tese doutorado)
CLEMENT, C.R.; BOVI, M.L.A. Padronização de medidas de crescimento e produção em experimentos com pupunheira para palmito. Acta Amazonica, Manaus, v.30, n.3, p.349-362, 2000. CRUZ, C.D.; REGAZZI, A.J. Modelos biométricos aplicados ao melhoramento genético. Viçosa: UFV, 1994. 390 p.

DEWEY, D.R.; LU, K.H. A correlation and pathcoefficient analysis of components of crested wheatgrass seed production. Agronomy Journal, v.51, n.1, p.515-518, 1959.

FANTINI, A.C.; NODARI, R.O.; REIS, M.S.; REIS, A.; RIBEIRO, R.J. Estimativa da produtividade de palmito em plantas de palmiteiro (Euterpe edulis Martius) a partir de características fenotípicas. Revista Árvore, v.21, n.1, p.49-57, 1997. FERREIRA, V.L.P.; BOVI, M.L.A.; ANGELUCCI, E.; FIGUEIREDO, I.B.; YOKOMIZO, Y.; SALES, A.M. Estudo dos palmitos das palmeiras e do híbrido de Euterpe edulis Mart. e Euterpe oleracea Mart. II. Avaliações físicas e químicas. Coletânea ITAL, Campinas, v.12, n.1, p.243-254, 1982a.

FERREIRA, V.L.P.; GRANER, M.; BOVI, M.L.A.; DRAETTA, I.S.; PASCHOALINO, J.E.; SHIROSE, I. Comparação entre os palmitos de Guilielma gasipaes Bailey (pupunha) e Euterpe edulis Mart. (juçara). I. Avaliações físicas, organolépticas e bioquímicas. Coletânea do ITAL, Campinas, v.12, n.1, p.255-272, 1982 b.

GOLDENBERG, J.B. El empleo de la correlación en el mejoramiento genético de las plantas. Fitotecnia Latinoamericana, v.5, p.1-8, 1968.

LEPSCH, I.F.; SARAIVA, I.R.; DONZELI, P.L.; MARINHO, M.A.; SAKAI, E.; GUILLAUMON, J.R.; PFEIFER, R.M.; MATTOS, I.F.A.; ANDRADE, W.J.; SILVA, C.E.F. Macrozoneamento das terras da região do rio Ribeira de Iguape, SP. Campinas: Instituto Agronômico, 1990. 181 p. (Boletim Científico 19).

MORA-URPÍ, J.; WEBER, J.C.; CLEMENT, C.R. Peach palm. Bactris gasipaes Kunth. Promoting the conservation and use of underutilized and neglected crops. 20. Rome: Institute of Plant Genetics and Crop Plant Research, Gaterleben and International Plant Genetic Resources Institute, 1997. 83 p.

MOREIRA, D.A. Caracterização fenológica, incremento semestral e produtividade de palmito para o manejo sustentado do açaizeiro (Euterpe oleracea Mart.). Jaboticabal: UNESP. 1998. 102 p. (Tese mestrado)

OBOH, B.O.; FAKOREDE, M.A.B. Interrelations among vegetative, yield and bunch quality traits in short-stem oil palm progenies. Euphytica, v.46, n.1, p.7-14, 1990.

OBOH, B.O.; FAKOREDE, M.A.B. Effects of weather on yield components of the oil palm in a forest location in Nigeria. Journal of Oil Palm Research, v.11, n.1, p.79-89, 1999.

OLIVEIRA, M.S.P.; LEMOS, M.A.; SANTOS, V.F.; SANTOS, E.O.; Coeficiente de caminhamento entre caracteres agronômicos e a produção de frutos em açaizeiro (Euterpe oleracea Mart.). Revista Brasileira de Fruticultura, Jaboticabal, v.22, n.1, p.6-10, 2000.

PRABHAKARAN, P.V.; NAIR, G.K.B.; THAMPI, A.P.; PILLAI, K.S.; NAIR, V.R.; NAIR, G.M.; PUSHPANGADAN, K.; SUKUMARAN, K.M.; PILLAI, G.R.; KOSHY, E.P. Forecast of coconut yield using biometric characters of young palms. Coconut Breeding and Management, v.1, p.243-246, 1991. 
RAMOS, M.G.; SCHALLEMBERGER, T.C.H.; MOLINARI, A.J. Normas técnicas do cultivo da palmeira-real-da-austrália para produção de palmito. Santa Catarina: EPAGRI, 1997. 16 p. (Sistemas de Produção 26).

REIS, M.S.; CONTE, R.; FANTINI, A.C.; NODARI, R.O. Caracterização do incremento em diâmetro de Euterpe edulis Mart. e implicações para o seu manejo em formações florestais secundárias. Revista Árvore, v.23, n.4, p.413-422, 1999. SAEG - Sistema para Análise Estatística e Genética (SAEG v.5.0). Manual de uso. Viçosa: UFVFunarbe, 1997.
SÁES, L.A. Resposta da bananeira "nanicão" à região do Vale do Ribeira. Piracicaba: ESALQ. 1995. 82 p. (Tese mestrado).

SIMMONDS, N.W. Principles of crop improvement. New York: Longman, 1979. 408 p. SINDHUMOLE, P.; IBRAHIM, K.K. Path analysis of oil yield in coconut (Cocos nucifera L.). Geobios Jodhpur, v.29, n.4, p.239-240, 2002. STEEL, R.G.; TORRIE, J.H. Principles and procedures of statistics. New York: MacGraw-Hill, 1980. $632 \mathrm{p}$.
TANIPUTRA, S.B.; MANURUNG, A. The possibility of using the number of leaflets in the oil palm for yield prediction. Buletin Perkebunan, v.19, n.3, p.119-127, 1998.

WRIGHT, S. Correlation and causation. Journal of Agricultural Research, v.20, p.557-585, 1921. 